\title{
Research on Development of Folk Snacks on the Verge of Losing Their Inheritance_A Case Study of "Jiliu" in Shandong
}

\author{
Hongyan Cai ${ }^{1,}{ }^{*}$, Lin Wang ${ }^{1}$, Mengchao $\mathrm{Ji}^{1}$, Yanhuan $\mathrm{Ma}^{1}$, Zheng Zhou ${ }^{1}$ \\ ${ }^{1}$ School of Humanities, Shandong Agriculture and Engineering University, Jinan, Shandong 250100, China \\ *Corresponding author. Email: caihongyan@sdaeu.edu.cn
}

\begin{abstract}
This paper uses the method of literature analysis to obtain the information of diet in Shandong Province from the local library and the government network by consulting the literature and related theories. It is found that many special foods are forgotten in the folk and they are on the verge of disappearing. At the same time, the researcher reviewed the research directions related to dietetic culture at home and abroad, and explored the cultural connotation, inheritance significance, and strategies of using "Jiliu" to develop the villages economy in Shandong. The purpose is to call on people to pay more attention to the inheritance and development of special foods in the folk.
\end{abstract}

Keywords: Jiliu; dietetic culture; inheritance and development

\section{INTRODUCTION}

Diet is the material basis for people's survival [3]. It is not only a simple solution to the problem of food and clothing, but also a model that is suitable for the region's prosperity based on the geographical environment [1]. Either physiologically or spiritually, the cultural significance given to human beings by diet is the most direct. Everyone has a sense of belonging. Eating activities will unconsciously show their identity with specific eating habits. Many traditional cultural behavior patterns are inherited in this daily eating activity.

The diet may seem simple, but in fact it contains so much cultural connotation [4]. Today, dietetic culture is generally regarded as a folk custom. What kind of dietetic culture a nation or a region has must correspond to a series of ecological structures, including the environment and the people living there [6]. What to eat, how to eat, and why to eat are not only related to people's needs and habits, but also reflect the folk customs there. "Eating" as an eternal topic in survival has always been the focus of researchers in various fields.

China has ancient civilization with a history of 5,000 years. China's culture can be said to be vast and profound. Since China's reform and opening-up policy was implemented in 1978, the exchanges between China and other countries have become increasingly frequent. China has paid much more attention to promote its cultures to the world while learning from different cultures. In 2001, China became a member of the World Trade Organization. Chinese economic and trade exchanges with other countries around the world are frequent. In 2010, the World Expo was grandly held in Shanghai, China. Since then, more and more foreign friends have turned their attention to China. On
November 6, 2013, the China Intangible Cultural Heritage Protection Association was established. It is affiliated with the Ministry of Culture and is a social organization and a legal corporate organization with the mission of protecting and inheriting China's intangible cultural heritage. The State Council of China approved the second batch of national intangible cultural heritage lists, with a total of 510 items, of which 30 items are catering items. Since 2006, there are eight traditional food making techniques selected into the first batch of national "intangible heritage" directories, and the second batch included 30 traditional making techniques of beverages and dishes including wine, tea, pickles, pasta, poultry and so on. Many people in Beijing prefer ErGuotou (a kind of wine in Beijing), sauce elbow, roast duck, braised lamb, pickles and so on, these making processes of the above food and wine have become a protected intangible cultural heritage, which is enough to show that dietetic culture is an important part of traditional Chinese culture, condensing the essence of traditional Chinese culture, and reflecting the light of the wisdom of the Chinese nation. In the process of spreading Chinese civilization to the world, dietetic culture should occupy an important place among them, but with the development of the economy, the researcher found that some dietetic culture has gone into exile in the folk and is facing the danger of being lost gradually, which is a great loss for cultures' inheritance and development.

\section{RESEARCH ON DIETETIC CULTURE AT HOME AND ABROAD}

The "culture" part of Chinese dietetic culture research is mostly related to science of Chinese history, but has not noticed the snacks that are about to be lost in our current life, and its research scope mostly covers the dietetic cultures' 
changes in different historical periods. For example, Chinese ancient dietetic culture includes: dietetic culture in the Three Kingdoms Period, dietetic culture in the Northern and Southern Dynasties, dietetic culture in the Han and Tang Dynasties, dietetic culture in the Tang Dynasty, dietetic culture in the Tang and Song Dynasties.

The study of dietetic culture in other countries of the world is biased towards the natural sciences related to different kinds of foods. The literature on dietetic culture abroad includes: food nutrition, technology and development about foods making, food safety [7], decomposition and analysis of food ingredients, food sales and management, etiquettes and customs related to food, the relationship between people and the environment reflected by dietetic culture, etc., but its research content is not broad enough.

To sum up, the fields of dietetic culture research at home and abroad is not wide and broad.

We have always been proud of Chinese cuisine and culture, but in its domestic markets and foreign markets, Chinese food is not what we imagined-getting perpetual inheritance and development. It turns out that the lack of publicity and the wrong conception of inheritance and development made some snacks almost lost and could not be known to the world.

\section{THE SIGNIFICANCE OF JILIU'S INHERITANCE AND DEVELOPMENT}

China's local specialties have a long historical background and deep cultural origin. Many local snacks have distinct local characteristics, and some are related to local customs, historical allusions, celebrity anecdotes, and historical events. With their wide varieties and different characteristics, it is entirely possible and capable to be developed into brand snacks, and even into world-renowned brand snacks. However, the idea of local specialties protection is outdated and developed independently, lacking the overall protection and development methods. As a result of improper inheritance, many local snacks are gradually disappearing, and related techniques are gradually being lost. It requires us to explore local snacks, pass on related making techniques, and then spread dietetic culture to domestic and foreign countries, creating a good atmosphere of dietetic cultures' inheritance and development.

Among many of the dietetic cultures, I found that there has one kind of diets that was popular in Shandong province, called "Jiliu", is now rarely known by even local people. It is often said that "culture needs to be inherited and culture needs to be developed." This statement also applies to dietetic cultures. Among them, "Jiliu" is one of the diets that needs to be inherited and developed.

The researcher launched an investigation and inquiry from the origin of "Jiliu" to the significance of its existence and inheritance, On the one hand, it is used to awaken local people's memories related to "Jiliu", to remember nostalgia, so that it can be passed on; on the other hand, it is also in response to the Chinese national "village revitalization" strategy. Through cooperation with local tourism agencies, it can attract foreign tourists, tell them the cultural stories behind foods, spread the local dietetic culture abroad, and then promote the exchange of Chinese and foreign dietetic culture and finally promote the development of rural economy. Dietetic culture must keep pace with the ages, review history, and play an important role on its economic significance.

\section{THE CULTURAL CONNOTATION BEHIND "JILIU"}

Shortly after the 18th National Congress of the Communist Party of China, General Secretary Xi Jinping explained to the world the Chinese dream of achieving the great rejuvenation of the Chinese nation, which aroused strong repercussions at home and abroad. Since then, Chinese people started with building dreams, chasing dreams and fulfilling dreams. In a large sense, dietetic culture reflects the needs to "tell a good Chinese story", and to build Chinese dreams, chase Chinese dreams, and fulfill Chinese dreams, we must not forget to review national history and learn from the hard-working older generations. Through learning about the dietetic culture, People from the world can understand the Chinese people 's worldview, outlook on life, values, and understand the Chinese people 's views on nature, history, the world, and the future. To a certain extent, they have paid much more attention to those ordinary and hardworking people's long journey to realize their dreams. "Jiliu" is a kind of snack widely spread in the folk of Shandong in the old days. Its pronunciation consists of two words, sounding like "Ji, Liu", which words are they? Nothing can be found in the Chinese dictionary. Only in recent years, researchers in the dietetic culture of Shandong cuisine have found two words to replace these two pronunciations. Few people still remember the making techniques of "Jiliu". In fact, "Ji" here is a multi-syllabary word in Chinese. It is pronounced "Ji" in the phrase "Jicai dumplings" that is one kind of dumplings made from vegetable "Jicai". It also has another pronunciation of "Qi", such as in the Chinese phrase "Biqi (commonly known as Chinese water chestnut), which can be eaten raw or cooked as a kind of fruit or medicine. So, what kind of snack is "Jiliu"?

Wild vegetables are necessities for making "Jiliu". In fact, its making method is relatively simple. In the old days of Shandong, in order to feel full, people usually picked a variety of wild vegetables from the field, washed them, marinated them with salt, mixed the coarse grains, made them into dumplings, and then steamed them in a pot. When eating, people dipped in mashed garlic with vinegar and soy sauce.

According to sayings from the folk, in addition to making people full, because the main raw materials of "Jiliu" are taken from a variety of wild vegetables that have medicinal functions and values, "Jiliu" will bring unexpected good effects to people's health. More importantly, there is no trace of oil in the cooking process, and it uses a very healthy cooking method. It is one kinds of simply steamed foods, 
returning to the most natural and authentic state of Chinese foods. It is easy for people to digest, and there is no loss of nutrition. where did "Jiliu" come from? There are two legends from the folk:

\subsection{Argument Related to BianQue}

BianQue is a divine doctor in ancient China. It is said that one year during the Spring Festival, the plague in Shandong Province was prevalent, and there are not enough foods for people, so the victims were everywhere. When BianQue saw this situation, he took a variety of wild vegetables and wild fruits with medicinal value, sprinkled with grain, and steamed in a large pot for everyone to eat. On the one hand, it can cure diseases, on the other hand, it can protect people from feeling hungry. Later, "Jiliu" became a folk snack with dual-purpose: curing diseases and preventing hungry from happening. Later, every spring, people digs wild vegetables and makes "Jiliu". Because this cooking method is owned by the Qi people, who steamed it. Shandong's dialects call "steam" as "Liu", such as "Liu" (means steaming in English) buns and distilling them before eating, so they call this kind of folk snack as "Qiliu".

\subsection{Argument Related to Cao Cao}

Cao Cao is the prime minister of Jinan, Shandong Province. It was said that when Cao Cao was preparing to start his military training in Jinan, his dear horse was ill, and Cao Cao was very sad, so he let his soldiers lead his horse to the wild field and let him die naturally. His dear horse went to the field and chewed the wild vegetables and wild fruits growing in the field. It is unbelievable that the horse recovered. Cao Cao was so joyed that he asked his soldiers to feed their horses with wild vegetables. Later, it was found that mixing wild vegetables with grains was also beneficial to the human's health. Therefore, Cao Cao often let soldiers eat this snack invented and cooked while "snacking" horses in "Qi field".

With the recent innovation of the Lu cuisine, which is one of the eight Chinese cuisines, and the return of Chinese tradition, "Jiliu", as a common national memory, has entered the vision of the researchers of the dietetic culture related to $\mathrm{Lu}$ cuisine once again. but it has added modern elements to its cooking techniques and methods. For example, besides wild vegetables often used in cooking in the old days, different varieties of vegetables can be used in cooking with the comments of Chinese herbal medicine. Meanwhile, the grain used in cooking is not limited to coarse grains.

\section{STRATEGIES OF PROMOTING RURAL REVITALIZATION AND DEVELOPMENT}

The inheritance and development of dietetic culture, on the one hand, makes everyone remember nostalgia and review history; on the other hand, it should also serve the economic revitalization of rural areas, so we can use this kind of dietetic culture to promote the revitalization and development of the countryside. Food is one of the important influencing factors for the development of tourism [2]. With the rapid development of tourism, tourists are no longer just satisfied with visiting natural sceneries and monuments, they try to experience and explore the cultural background of tourist destinations. Food not only meets the basic physiological needs of tourists, but also meets the higher spiritual needs of them. Most tourists try to get close to local cultures. Therefore, how to combine regional dietetic culture with tourism and how to develop them has gradually attracted attentions of the academic circles. Therefore, on the one hand, natural landscape resources can be used to introduce the rural areas of Shandong to Chinese and foreign tourists, to promote the development of tourism in poor rural areas. Meanwhile, tour guides can be trained to be familiar with the "Jiliu" culture in order to spread it, and to strengthen the exchange of dietetic culture between China and other foreign countries. On the other hand, we can use various ways such as TV reports, published articles, documentary videos, to establish Chinese and foreign tourists' correct understanding of Chinese dietetic culture. We can also attract foreign tourists to make and taste "Jiliu" personally so that more Chinese and foreign tourists can understand "Jiliu" deeply. Through all the above ways, we can achieve the goals of investing foreign capitals and increasing the development of rural economy.

\section{CONCLUSION}

The researcher only takes Shandong's "Jiliu" as an example, reviewing the historical origin of its appearance, and studying the historical, cultural, and economic significance of its existence, inheritance and development, in order to arouse the attention of friends at home and abroad to attract their interests on China 's extensive and profound dietetic culture. In fact, there are countless snacks that are hidden in the folk. They also have their own profound senses of existence, inheritance and development. How to make these foods continue to be inherited and developed, how to tell Chinese stories related to these foods to more people, and how to develop rural economy, all of which are worth us thinking deeply [5].

\section{REFERENCES}

[1] Li Yang. Analysis of the Development of Dietetic Culture Tourism Resources [J]. Academic Exploration, 2001 (06): 67-70.

[2] Ruixin Liu. A Study on the Development of Dietetic Culture in the Tourism Industry [J]. Journal of Gansu Administration College, 2003 (04): 118-120. 
[3] Zhuangyi Wu. Research on the Interactive Development of Catering Industry and Tourism Industry in the Perspective of the Tourism [D]. Hunan Normal University, 2006.

[4] Yuxiang Song. A Study on Chinese Dietetic Culture [J]. Art Science and Technology, 2014,27 (02): 126.

[5] Rongchun Zhang. A Study on the Development of Dietetic Culture in the Tourism Industry $[\mathrm{J}]$. China Business, 2012 (12): 164-165.

[6] Zhaorong Peng. Anthropology of Diet [M]. Beijing: Peking University Press, 2013.

[7] Suhua Chen. Human Diet Culture [M]. Shanghai: Shanghai Cultural Publishing House, 2008. 